\title{
ESTUDO DE POLÍTICAS PÚBLICAS A PARTIR DE NARRATIVAS: 0 CASO DO PROCESSO DE ELABORAÇÃO dO PROGRAMA DE REVITALIZAÇÃO E DESENVOLVIMENTO DA REGIĨO CENTRAL HISTÓRICA DE SANTOS
}

\author{
Public policy studies using narratives: the case of Santos' Revitalization and Development Program for the \\ Historical Downtown Region
}

Resumo

Reconhecendo a existência de diferentes perspectivas sobre como conduzir estudos sobre políticas públicas, este artigo traz como proposta abordagem teórico-metodológica cujas bases são: a noção de Alvesson e Kärreman de pesquisa social como construção de enredos de suspense tendo o objeto empírico como disparador; o conceito de Spink de campo-tema; e, principalmente, o levantamento e estudo das narrativas conforme indicado por Czarniawska. 0 caso escolhido para explorar essa abordagem é o processo de elaboração do Programa de Revitalização e Desenvolvimento da Região Central Histórica de Santos, também conhecido como programa Alegra Centro. Sugere-se que o instrumento de estudo de narrativas demonstra-se capaz de reconhecer a complexidade do campo-tema e, nesse sentido, das políticas públicas que são objeto de nossos estudos, lançando luz e mapeando questões de pesquisa em diálogo com os atores que com elas se relacionam no cotidiano.

Palavras-chave: Políticas públicas, narrativas, público, centros históricos, revitalização.

Lúcio Nagib Bittencourt - lucio.bittencourt@gvmail.br

Graduado em Administração Pública na FGV-EAESP (2006); mestre em Administração Pública e Governo pela FGV-EAESP (2010).

Doutorando em Administração Pública e Governo na EAESP-FGV, São Paulo, SP, Brasil.

Isleide Arruda Fontenelle - isleide.fontenelle@fgv.br

Doutora em Sociologia (USP, 2000), com pós-doutorado em Psicologia Social (PUC-SP, 2004) e Visiting Fellow (Essex University, 2010-2011). Professora e pesquisadora dos programas de graduação e pós-graduação da FGV-EAESP, integrante do Departamento de Fundamentos Sociais e Jurídicos da Administração.

Artigo submetido no dia 16.08.2010 e aprovado em 11.07.2012

\section{Abstract}

Acknowledging the existence of different perspectives about how to study public policies, this paper proposes a theoretical-methodological approach based on: Alvesson and Kärreman's notion on social science inquiry as constructing mysteries based on empirical matters; Spink's concept of "theme-field"; and, most of all, the gathering and studying of narratives, according to Czarniawska's work. The case study chosen to explore this approach is the elaboration process of the Program for Revitalization and Development of the city of Santos Central Historical Region, also known as Cheer Up Centre. We suggest that the narrative studies shows itself capable of acknowledging the complexity of the theme-field and, in that sense, of the public policies that are object of our studies, enlightening and mapping research questions in dialogue with actors that are related to them in everyday life.

Keywords: Public policy, narratives, public, historic centres, revitalization. 


\section{INTRODUÇÃO}

Os estudos de políticas públicas podem ser caracterizados por considerar estratégias de ação pública, tanto do ponto de vista institucional como dos grupos que participam e não participam desses processos, e também os objetivos e as finalidades em disputa, seus efeitos e as dinâmicas relacionadas à tomada de decisão (SARAVIA, 2006). Farah (2011) identifica também diferentes abordagens no desenvolvimento desses estudos, como a considerada mainstream, cujo foco está na política pública como técnica separada dos aspectos políticos, no estabelecimento de hipóteses a serem verificadas no campo e na crença da neutralidade do pesquisador e de seus métodos científicos, e a chamada pós-positivista, marcada pelo rompimento da separação entre aspectos políticos e técnicos e pela recusa da ideia de fatos em favor de interpretações sobre o social, compreendendo a complexidade das questões públicas, conforme argumenta Fischer (1998).

É justamente em função do que considera a complexidade dos temas de investigação em administração pública e políticas públicas que Frederickson (1997) chama atenção para a diferenciação entre administração pública e administração de governos:

When linked to a governmental definition of public administration, the practices of government - voting, politics, budgets, personnel management, and service delivery - become the subject matter. When public administration is defined as all of the means by which the public functions, including government, the subject changes to patterns of human organization: the values of groups and organizations and how these values are expressed; how governments function; and how governmental, nongovernmental, and business organizations interact. We live in a world of shared power in which governmental, quasi-governmental, nonprofit, and private organizations engage in policymaking and policy implementation. (FREDERICKSON, 1997, p. 5)

Reconhecendo esse debate, este trabalho propõe o estudo de políticas públicas por meio de narrativas enquanto método interessante para ampliar o diálogo que proporcionamos nas pesquisas desenvolvidas neste campo. $O$ caso escolhido foi o processo de elaboração do Programa de Revitalização e Desenvolvimento da Região Central Histórica de Santos, também conhecido como programa Alegra Centro. Nesse sentido, está estruturado da seguinte maneira: em primeiro lugar, apresentamos as bases da abordagem teórico-metodológica que sustenta o desenvolvimento do trabalho e que, por consequência, traz a apresentação do caso em estudo conforme a investigação vai se desdobrando; em seguida, apresentamos a leitura das narrativas, descrevendo seu processo de levantamento, apresentando uma primeira aproximação aos entrevistados e sugerindo a diferenciação entre macro e micronarrativas como meio para construir diálogo entre as diferentes histórias; por fim, propõe-se problematização com base na reflexão sobre as diferentes perspectivas sobre público presentes nas narrativas. Destacamos que este trabalho não trata de qual narrativa teria mais valor ou seria mais verdadeira que a outra; nosso objeto de estudo é como os atores constroem seus posicionamentos sobre os processos e as questões relacionadas à elaboração de uma política pública. 


\section{ABORDAGEM TEÓRICO-METODOLÓGICA}

A abordagem para estudos na área das ciências sociais indicada por Alvesson e Kärreman (2007), que relaciona pesquisa ao encontro de inconsistências - breakdowns - e à construção de enredos de suspense mysteries - a desvendar, tendo o material empírico como objeto disparador, constitui aspecto fundamental para este trabalho. Com o intuito de estruturar e inspirar processos de pesquisa que tenham por base esses conceitos, sem, contudo, restringir o método a um manual rígido incontestável, os autores detalham seis "nós": (1) a familiarização com o tema a ser estudado de maneira razoavelmente aberta; (2) o encontro ou a construção de inconsistências, implicando o aparecimento de material que não pode ser explicado pela teoria disponível; (3) a passagem da inconsistência para o mistério, com base em (a) a relevância do que foi encontrado por análise empírica, (b) os problemas relacionados à teoria anterior e (c) as pistas que podem levar à formulação de um enredo de suspense; (4) - aprofundamento dos trabalhos na busca de uma nova abordagem teórica por meio de novas incursões empíricas; (5) a reformulação do enredo de suspense trazido pela nova interpretação criada em relação ao objeto de pesquisa; e (6) o desenvolvimento de uma resolução para o mistério proposto, com o intuito de que possa ampliar as fronteiras do conhecimento sobre o problema de pesquisa (ALVESSON; KÄRREMAN, 2007, p. 12701272).

O objetivo adotado para este trabalho foi alcançar o terceiro "nó". Nele, a pergunta de pesquisa deveria estar fundamentada, 0 material empírico levantado e as referências bibliográficas (re)estudadas - refletindose sobre suas possíveis limitações para explicar a dinâmica envolvida no objeto em investigação - tornando-se "pistas" para a construção de um enredo de suspense, um "mistério", que poderia inspirar futuras investigações.

Assim como a abordagem de Alvesson e Kärreman (2007), outro pressuposto metodológico sobre o qual se sustenta esta pesquisa está na concepção de campo-tema (SPINK, 2003), devido às dinâmicas nela previstas:

Campo é o campo do tema, o campo-tema; não é o lugar onde o tema pode ser visto - como se fosse um animal no zoológico - mas são as redes de causalidade intersubjetiva que se interconectam em vozes, lugares e momentos diferentes, que não são necessariamente conhecidos uns dos outros. Não se trata de uma arena gentil onde cada um fala por vez; ao contrário, é um tumulto conflituoso de argumentos parciais, de artefatos e materialidades. (SPINK, 2003, p. 36).

Nesse sentido, tornou-se necessário para a realização desta pesquisa escolher estratégia adequada para identificar as diferentes redes de causalidade presentes no campo-tema do qual ela faz parte, já vislumbrando que resultados poderiam ser apresentados após sua conclusão:

Precisamos aprender que ser parte do campo-tema não é um fim de semana de pesquisa participante e muito menos uma relação de levantamento de dados conduzidos num lugar exótico, masé, antes de mais nada, a convicção moral que [...] estamos nesta questão, no campo-tema, porque pensamos que podemos ser úteis. Ser útil pode ser algo como o apoio ao debate ou, dado que nenhuma teoria ou 
argumento viaja por conta própria, ajudar os saberes e conhecimentos presentes a viajar para que outros possam conectá-los com outras ideias e possibilidades dentro do processo de coletivização. Pode ser também a contribuição de trazer outras vozes para o debate, de mostrar outras posições e outros argumentos. (SPINK, 2003, p. 27).

A partir deste momento, em que adotamos a postura em prol de conectar as diferentes vozes presentes em um campotema, percebendo como contribuição da pesquisa acadêmica o colocar em debate as diferentes ideias, saberes e percepções nele presentes, o conhecimento que surge a partir do estudo de narrativas aparece de maneira privilegiada, em contraste com a perspectiva lógico-científica:

Narrative knowledge tells the story of human intentions and deeds, and situates them in time and space. It mixes the objective and the subjective aspects, relating the world as people see it. In contrast, the logico-scientific (paradigmatic) knowledge, 1) looks for casual connections to explain the world, 2) out of such connections formulates general laws, 3) contains procedures ("paradigms") to verify/falsify its own results. It has also a distinct style, which I tried to imitate here. (CZARNIAWSKA, 2000, p. 3).

Dessa maneira, a abordagem teóricometodológica desenvolvida neste trabalho buscou colocar o objeto empírico em primeiro plano desde o momento inicial, trazendo dele o contexto com o qual se relaciona, colocando em experimentação uma opção metodológica para o estudo de políticas públicas, em consonância com abordagens que "procuram romper a separação entre o analista de políticas e os atores envolvidos com as políticas públicas" (FARAH, 2011, p. 823) e que tratam de reconhecer que não apenas a comunidade científica é capaz de trazer contribuições para a compreensão de problemas públicos (FISCHER, 1998, p. 134), como também os atores que com eles se relacionam no seu cotidiano. O objetivo, portanto, foi de, a partir da percepção de que esta pesquisa é mais uma voz no campotema, colaborar para que as diferentes vozes, narrativas e interpretações possam conversar (SPINK, 2003), desde as dos atores envolvidos diretamente na política pública, como a própria literatura que usamos como referência:

Sem dúvida nossos estilos acadêmicos de narrar estão ainda muito presos aos pressupostos científicos préconstrucionistas e precisamos estar preparados para abrir mão da estrutura e estilos convencionais das dissertações, teses, artigos e apresentações quando estes não ajudam a construir um diálogo inicial entre o campo-tema e as demais pessoas direta ou indiretamente presentes incluindo os não-presentes-mas-presentesnas-narrativas. (SPINK, 2003, p. 39).

Para resgatar os eventos envolvidos no processo de elaboração dessa política pública, portanto, partimos da concepção de que os diferentes atores (se) constroem e reconstroem subjetivamente suas relações com o objeto em investigação, criando uma rede de significados que incluem contradições, encontros, inconsistências, fissuras e debates, reconfigurados, constantemente, pela ação dos próprios sujeitos. O mecanismo adotado para a identificação desses "nós" foi o uso das narrativas, ou seja, do estudo sobre como os atores contam suas histórias, acompanhando 
a metodologia desenvolvida por Czarniawska (2004). Em seus estudos, a autora defende que as pesquisas com base nas narrativas devem se basear não na busca por relações de causa e efeito, ou por regularidades, mas em investigar a criação de um texto. Nesse sentido, há relação entre as narrativas e o campo de estudos organizacionais:

Narrating is organizing, and although organizing is more than narrating, even that part of it that is non-narrative can become topic of a narration. One cannot repair a machine by telling how it was done but one can always tell a story about the repair. (CZARNIAWSKA, 2000, p. 4).

Assim, a autora propõe como movimento no estudo de narrativas (a) coletar histórias, provocar o contar histórias e observar como as histórias estão sendo criadas para, em seguida, (b) interpretar - o que elas dizem? analisar - como elas dizem? - e desconstruir essas histórias, sob o objetivo de (c) construir a sua própria história enquanto pesquisador, tornando-se capaz de colocá-la em contraposição às outras histórias, colaborando para a geração de conhecimento sobre um determinado assunto (CZARNIAWSKA, 2000).

$O$ instrumento das narrativas está em sintonia com as complexas construções de sentido em curso no campo-tema Alegra Centro, entendendo-as como um tipo de discurso marcado pela temporalidade e pela presença de uma trama (ALVES; BLIKSTEIN, 2006). Por meio dele, foi possível buscar a narrativa de empresários de diferentes setorese associações, e também de diferentes membros da administração pública local nos últimos anos, com relações e visões distintas sobre o processo de elaboração de um programa de "revitalização". Ainda que não partindo de um mapeamento prévio nesse sentido - a saber, um grupo de atores os quais "deveriam" ser entrevistados - o importante é perceber que a reunião dessas múltiplas narrativas permite confrontar diferentes visões de público presentes nessa ação do governo local.

Dessa maneira, sublinhamos que a lista de atores a serem entrevistados não foi predefinida: sua função era recuperar - e não limitar - sob a voz dos próprios atores envolvidos no processo, sua participação no processo de elaboração do Alegra Centro, sua visão sobre esse processo, seus eventoschave e o mapeamento dos demais atoreschave de acordo com a narrativa de cada ator entrevistado, possibilitando confrontar as narrativas sobre o processo/as ações que levaram à sua criação. A realização das entrevistas, portanto, esteve subordinada ao primeiro passo metodológico, o qual passa a ser descrito a seguir.

\section{LEITURA DAS NARRATIVAS}

$\mathrm{Na}$ seção anterior, foi possível apresentar a abordagem metodológica adotada para a realização desta pesquisa. De maneira geral, cabe destacar um ponto específico: o que indica a possibilidade de estudar, investigar e avaliar o processo de elaboração de políticas públicas com base na voz dos próprios atores e nas narrativas que são construídas por eles a partir de seus posicionamentos dentro do campo-tema (SPINK, 2003). Entendemos por narrativas um tipo de discurso marcado pela temporalidade, pelo encadeamento de eventos críticos e pela presença de uma trama (ALVES; BLIKSTEIN, 2006). Para fins deste trabalho, a análise dessas narrativas seria pontuada pelas etapas de (i) coleta de histórias por meio de entrevistas e (ii) leitura das narrativas levantadas baseada nos 
conceitos de (a) explicação - caracterizada pela reprodução do texto narrado, (b) explanação - fase de desconstrução do texto, e (c) exploração - que consiste no momento no qual o pesquisador passa a construir o próprio texto, sua própria história (CZARNIAWSKA, 2004).

Nesse sentido, surgiu um desafio para o início dos trabalhos: uma vez colocadas em primeiro plano as vozes dos próprios atores, antes mesmo de desenvolver a parte teórica da pesquisa, qual seja discutir os diferentes sentidos de público presentes em um processo de elaboração de uma política pública, por onde começar?

Tendo em vista o prazo abreviado disponível para o desenvolvimento do projeto e as dificuldades frequentemente presentes nos processo de agendamento e realização de entrevistas - como a adequação às agendas dos entrevistados, os pedidos de adiamento ou, ainda, o seu não comparecimento, por vezes forçando a dilatação do tempo previsto para essa etapa - optamos pela adoção de dois pontos de partida simultaneamente. Em primeiro lugar, por se tratar de uma política pública municipal, solicitamos entrevista com o então chefe do poder executivo local; por outro lado, devido ao objeto desta investigação ser o programa Alegra Centro, cuja data de criação remete ao ano de 2003, durante outra gestão, buscamos contato com quem à época chefiava o poder executivo local.

Como resultado, a atual gestão municipal indicou um de seus secretários para a entrevista, enquanto o anterior chefe do poder executivo local deixou agendada entrevista para as semanas seguintes.

A aposta nesse processo se dava da seguinte forma: a partir das próprias entrevistas, seria possível observar que os atores, ao propor suas narrativas sobre 0 processo de elaboração da política pública, fariam referência a outros atores cujos papéis fossem relevantes no processo desde sua perspectiva, proporcionando que, a cada entrevista, fosse possível ter à disposição uma nova peça para a montagem do quebracabeça que é o processo em questão; um mapeamento. É importante ressaltar que, ao evocar a metáfora do quebra-cabeça, não pretendemos sugerir sequer a possibilidade de que ele se tornaria, eventualmente, completo; ao contrário, procuramos demonstrar que, a partir dessa abordagem metodológica, é possível, adotando um ponto de partida, buscar e encontrar novas partes de uma narrativa, no sentido da composição de uma "macro-narrativa" - não por isso consensual. Ainda assim, trata-se de peças sem uma forma predefinida, que nem sempre se encaixam - chegando, às vezes, a parecer que sequer são de um mesmo jogo. À medida que a coleção dessas peças se desenvolve, entretanto, a imagem em formação torna-se progressivamente mais compreensível - no que tange aos seus pontos de encontro e desencontro.

A comparação aqui, portanto, vai em direção ao debate sobre a macro e a micro-história, conforme desenvolvido em Revel (1998): a sequência das entrevistas apresentam encaixes - encadeamentos, indicam imagens e, portanto, relações gerais entre as peças; um olhar mais detido a um ponto específico, por outro lado, por mudar a perspectiva - em acordo com a voz e as narrativas dos próprios atores - pode mudar completamente a visão que se tem da composição do jogo. Nesse sentido, não se trata de hierarquizar a "macro" ou a "micronarrativa", mas perceber que seus olhares simplesmente apontam para composições diferentes. Como em Sonhos (1990), filme de Akira Kurosawa no qual o observador se 
descobre capaz de transcender as imagens produzidas por Van Gogh, caminhando por/ em suas telas e surpreendendo-se com os detalhes das pinceladas vistas sob outras perspectivas, também nesta metodologia para pesquisa social há mais, além da "macronarrativa" que encontramos. Em vez de negá-la, porém, tratamos de reconhecer (n)ela o próprio indicativo das lutas discursivas em curso no campo-tema (HARVEY, 2003). São essas lutas discursivas que podem vir a indicar as diferentes perspectivas de público no processo de elaboração dessa política pública.

Essa reflexão é de grande relevância para os resultados que começam a ser apresentados a seguir. Em primeiro lugar, portanto, abordaremos a "macro-narrativa" que foi possível encontrar após a realização de dez entrevistas no ano de 2009. Em seguida, propomos a problematização dessa "macronarrativa" a partir das "micro-narrativas" levantadas nas entrevistas, resultando em olhares bastante distintos, por vezes do processo como um todo, por outras de eventos específicos em seu desenrolar.

Antes, contudo, consideramos interessante explorar mais detalhadamente a caracterização do conjunto dos entrevistados, tendo em vista a apresentação de como as correlações se deram.

\subsection{Aproximações ao conjunto de entrevistados}

Conforme destacado anteriormente, totalizaram-se 10 (dez) entrevistas realizadas ao longo do ano de 2009. Foram 2 ex-chefes do poder executivo local, 4 membros da administração pública em cargos de confiança, como secretários e chefes de departamento de diferentes gestões, 3 empresários e 1 membro de movimento social. A cada entrevista, novos atores foram citados, e optamos pelo seguinte agrupamento para ilustração dos tipos mais frequentes:

a) Instituições de governo no nível municipal, nas quais estão reunidas referências à Administração Direta Municipal, como a prefeitos e secretários, mas também aos diferentes conselhos municipais, como COPLAN (Conselho do Plano Diretor), CMDU (Conselho Municipal de Desenvolvimento Urbano), CDES (Conselho de Desenvolvimento Econômico de Santos) e CONDEPASA (Conselho de Defesa do Patrimônio Cultural de Santos), além da própria esfera Legislativa Local, como Vereadores e a Câmara Municipal de Vereadores. Membros de partidos políticos com atuação local também estão neste grupo;

b) Instituições de governo no nível estadual, nas quais ficam as indicações ao Governo do Estado de São Paulo, à CDHU (Companhia de Desenvolvimento Habitacional e Urbano) e ao Conselho de Defesa do Patrimônio Histórico, Arqueológico, Artístico e Turístico (CONDEPHAAT);

c) Instituições de governo no nível federal, contendo as citações ao IPHAN (Instituto do Patrimônio Histórico e Artístico Nacional) e ao Programa Monumenta;

d) Empresas, reunindo imprensa local, consultorias em arquitetura e restauro, construtoras, bancos, seguradoras, comércio, agências de turismo, escritórios de advocacia e de negócios portuários, além das referências a profissionais sem especificar a empresa, como "empresários do café" e "arquitetos";

e) Associações de Empresários, nas quais estão agrupados Câmara dos Dirigentes Lojistas, Associação Comercial de Santos, Associação Centro Vivo, Sindicato do Comércio Varejista da Baixada 
Santista, Associação dos Empresários da Construção Civil da Baixada Santista, Rotary Club de Santos, Viva o Centro, CREA e Lions Clube de Santos;

f) Instituições de Ensino, para as referências à Universidade Católica de Santos (UNISANTOS) e a "universidades", sem especificação;

g) Instituições Religiosas, compreendendo a Igreja do Valongo;

h) ONGs, nas quais está a Fundação Roberto Marinho, o Instituto Elos e Ambienta Assessoria e Desenvolvimento Local;

i) E, por fim, Movimentos Sociais, nos quais se apresenta a Associação dos Cortiços do Centro.

Devem-se justificar três aspectos desse agrupamento. Em primeiro lugar, os grupos referentes a instituições de governo nos três níveis federativos envolveram não apenas a administração direta mas também outros tipos de instituições, como os conselhos ou programas gerenciados especificamente por um dos entes federativos. Em seguida, há o esforço para não recorrer ao conceito de Terceiro Setor como um termo "guarda-chuva" para organizações não lucrativas, reconhecendo o atual debate sobre o tema (ALVES, 2002), e, mais importante, no que se refere a reunir sob um destino comum organizações de diferentes naturezas sob o conceito de Sociedade Civil (ALVES, 2004). Dessa maneira, definiramse como Associações de Empresários as organizações que foram descritas nas próprias narrativas como organizações formadas por atores assim referidos, até mesmo para organizações como o Rotary Club de Santos ou o Lions Clube de Santos, que poderiam ser consideradas filantrópicas (ALVES, 2002), além do próprio CREA, o qual aparece vinculado à Associação dos Engenheiros e Arquitetos de Santos (AEAS). No mesmo sentido, optou-se por destacar as citações referentes a instituições de ensino - notoriamente as universidades - e instituições religiosas. Por fim, o grupo ONGs foi escolhido para reunir "organizações que se dedicam a promover o desenvolvimento econômico e social, tipicamente em nível comunitário e de base" (ALVES, 2002, p. 4 ), enquanto movimentos sociais seguem o conceito trazido por Snow e Soule (2009), em que são vistos em função de cinco elementos chave: (1) desafiam ou defendem estruturas ou sistemas de autoridade vigentes; (2) são ações coletivas; (3) atuam, em diferentes graus, fora de arranjos institucionais ou organizacionais vigentes; (4) operam com algum grau de organização; e (5) tipicamente atuam com algum grau de continuidade (SNOW; SOULE, 2009, p. 6).

Como resultado, passa a ser possível observar um total de 141 referências, sendo que os grupos mais citados foram os associados às Instituições de governo no nível local, Associações de Empresários e Empresas, com 59, 31 e 25 citações, respectivamente, ou seja, $82 \%$ do total de indicações a outros atores. Os demais grupos, ONGs, Instituições de governo em nível estadual, Movimentos Sociais, Instituições de Ensino, Instituições de governo em nível federal e Instituições Religiosas, se somados, chegam a 26 referências, número semelhante ao agrupamento de Empresas. Dessa maneira, é possível notar uma concentração, nas narrativas, dos campos de relações entre governança local e empresários e suas associações, no interior do processo de elaboração da política pública em investigação. 
Tabela 1 - Números de referências por agrupamento de Organizações

\begin{tabular}{|c|c|c|}
\hline Tipo & $\begin{array}{c}\mathrm{N}^{\circ} \text { de } \\
\text { Citações }\end{array}$ & $\%$ do Total \\
\hline Instituições de governo no nível municipal & 59 & $42 \%$ \\
\hline Associações de Empresários & 31 & $22 \%$ \\
\hline Empresas & 25 & $18 \%$ \\
\hline ONGs & 10 & $7 \%$ \\
\hline Instituições de governo no nível estadual & 7 & $5 \%$ \\
\hline Movimentos Sociais & 3 & $2 \%$ \\
\hline Instituições de Ensino & 3 & $2 \%$ \\
\hline Instituições de governo no nível federal & 2 & $1 \%$ \\
\hline Instituições Religiosas & 1 & $1 \%$ \\
\hline TOTAL & 141 & $100 \%$ \\
\hline
\end{tabular}

Fonte: elaborado pelos autores

Conforme destacamos anteriormente, entretanto, as referências encontradas nas narrativas não necessariamente indicavam vinculação entre atores e instituições. É importante destacar que, ao se observar os atores citados nominalmente nas narrativas levantadas, todososqueestiveram presentesem ao menos metade (cinco) do total de narrativas (dez) foram entrevistados, excetuando-se os atores já falecidos e também o então chefe do poder executivo local, que indicou um secretário municipal para a entrevista.

Por fim, é possível elaborar um novo quadro (Figura 1), desta vez ilustrando a rede configurada pelas entrevistas e os atores presentes no processo em investigação, sendo que as relações estabelecidas têm por base o processo de citação presente ao longo das narrativas. Outra maneira de respeitar as entrevistas é a de acrescentar como pano de fundo as atuações institucionais desses atores, procurando dar sequência à maneira como as referências surgiram ao longo deste levantamento. Nele, observa-se em vermelho o então chefe do poder executivo local, por ser o ator mais citado, que não concedeu entrevista, mas indicou um secretário municipal. Este, assim como ex-chefes do poder executivo local e ex-secretários municipais aparecem com a cor verde, indicando relação com o governo local, embora de diferentes gestões (para referência, optamos por ilustrar as gestões mais distantes no tempo como espacialmente mais distantes, no sentido para baixo, da gestão do governo local vigente na época da entrevista. Outro ex-secretário e, na ocasião, chefe de departamento em secretaria municipal, por sua vez, aparecem com o mesmo verde, mas com efeito de gradação em seu preenchimento. Isso porque esses atores podem ser entendidos como de caráter mais híbrido entre suas atuações como empresários - um como membro da Associação Centro Vivo e outro por meio de consultoria em arquitetura e restauro - e como membros do governo local. Já com a cor laranja estão agrupados os empresários do ramo do café, da construção civil e do comércio, os quais, por sua vez, também estiveram relacionados com atuações em associações de empresários, como a Associação Centro Vivo, a Associação Comercial de Santos, a Associação 
dos Empresários da Construção Civil da Baixada Santistas, o Sindicato do Comércio Varejista da Baixada Santista e a Câmara dos Dirigentes Lojistas. Por fim, em azul está o único movimento social indicado nas narrativas, representando a Associação dos Cortiços do Centro. A concentração de linhas conectando os empresários e os membros dos governos mais recentes indica que há maior número de referências entre esses atores. São reconhecidos, entretanto, outros atores como participantes no processo de elaboração do programa Alegra Centro, conforme o coletivo das narrativas.

Figura 1 - Rede de atores entrevistados compondo parcialmente o campo-tema

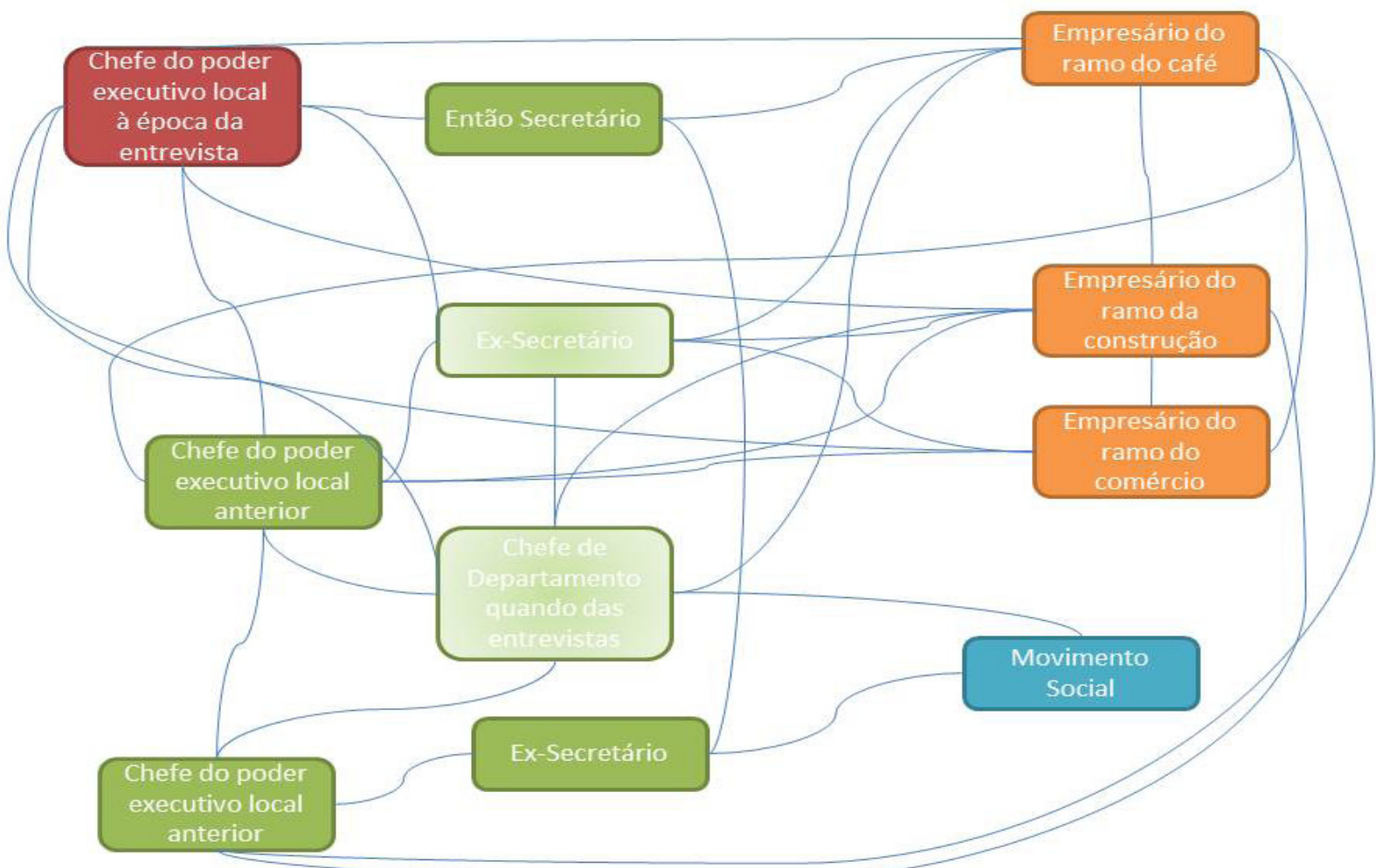

Fonte: elaborado pelos autores

\subsection{A macro-narrativa sobre a elaboração do programa alegra centro}

Dando início ao primeiro passo metodológico para leitura de narrativas, conforme sugerido por Czarniawska (2004), buscamos, neste estágio, compreender qual é a ideia geral - ou a composição - presente nas diversas narrativas sobre o processo de elaboração do programa Alegra Centro, ou seja, sua "macro-narrativa". Reforçamos, mais uma vez, que esse esforço não tem qualquer objetivo de resumir as narrativas ou apontálas como consensuais; ao contrário, os pontos em conflito ou de desencontro entre as peças do quebra-cabeça serão explorados na seção seguinte. O Quadro 1 a seguir ilustra o que podemos apresentar por "macro-narrativa" desse processo, com base na voz dos atores: 
Estudo de políticas públicas a partir de narrativas: o caso do processo de elaboração do Programa de Revitalização e Desenvolvimento da Região Central Quadro 1 - "Macro-narrativa” do processo de elaboração do programa Alegra Centro

Santos, cidade reconhecidamente histórica - devido à sua posição de segunda vila mais antiga a ser fundada no Brasil -, viveu período de destaque - ou sua belle époque - no início do século $\mathrm{XX}$, quando a riqueza trazida pelo comércio do café significou processo acentuado de desenvolvimento. Esse movimento deixou marcas no centro da cidade, o qual, em virtude da proximidade com o porto, veio a concentrar instituições de negócios que, consequentemente, passaram a caracterizar sua paisagem urbana.

Ao longo deste século XX, entretanto, a cidade se desenvolveu em outros sentidos, tanto do ponto de vista das atividades econômicas quanto da ocupação de novos espaços, o que resultou na queda da atividade comercial na região central. Este evento, ao mesmo tempo, resultou na degradação daquele espaço, que passou a ser percebido pela população santista, tristemente, como abandonado.

Após a redemocratização da cidade, em 1984, as gestões municipais passam a adotar medidas pontuais de intervenção nesta situação do centro da cidade, sendo que todas elas colaboraram de alguma forma para a recuperação do espaço. Ao mesmo tempo, outro processo transcorria, o qual resultaria na elaboração de uma política pública específica para a resolução do problema. Por um lado, ao longo da década de 1990, um grupo de empresários passou a se reunir buscando novas perspectivas de desenvolvimento para a área central de Santos, focando na necessidade de se preservar a história local retratada em diversos edifícios, ainda presentes - embora abandonados ou deteriorados - símbolos do passado glorioso vivido pela cidade. Essa situação levou à criação da Associação Centro Vivo, em 1994, inspirada na Associação Viva o Centro, que buscava a revitalização da região central de São Paulo, naquele mesmo período. Esta associação, entretanto, logo se confirma em um movimento de opinião, que passa a construir um processo de convencimento, na cidade, de que era importante e necessária uma intervenção no centro.

Paralelamente, assume em 1997 uma gestão no governo local comprometida com essa questão e que progressivamente passa a agir em direção à elaboração de um programa específico. Após ampla discussão com a sociedade civil em audiências públicas e reuniões nos conselhos municipais, chegou-se à proposta do programa Alegra Centro. A grande novidade trazida por essa proposta foi a de oferecer incentivos fiscais e, portanto, vantagens, para que o empresário - ou o empreendedor - buscasse levar o seu negócio para o centro da cidade, desde que obedecendo a regras de preservação do imóvel no qual ele se instalasse, conforme previsto em legislação. Dessa maneira, o grande problema que o programa visa solucionar é o esvaziamento, do ponto de vista da atividade econômica, na região central de Santos. Além disso, outros equipamentos públicos passaram a ser restaurados, tendo como objetivo que o poder público desse o exemplo ao empresariado local, demonstrando confiança no processo e realizando, ele mesmo, os primeiros investimentos.

O momento de sua aprovação em lei pela Câmara Municipal de Vereadores, entretanto, foi bastante difícil, resultando em demora de mais de um ano até sua resolução em favor do projeto. Nesse momento, a sociedade civil desempenhou papel importante no sentido de apoiar e convencer a população e, consequentemente, os vereadores, de que se tratava de um importante projeto para a cidade. A partir de então, o centro inicia seu processo de recuperação, demonstrando o sucesso do programa Alegra Centro.

Fonte: elaborado pelos autores 
Essa história pode ser entendida como uma narrativa porque, conforme aponta Czarniawska (2004), trata-se de uma série de eventos/ações encadeados cronologicamente e que, além disso, são parte de uma trama, no sentido de que conta a passagem de um momento de equilíbrio para outro. $\mathrm{O}$ primeiro seria os tempos áureos do café como retrato da riqueza da cidade estampada no centro, tido como um espaço privilegiado na cidade; a passagem, por sua vez, afirma que algo acontece leva o centro a entrar em decadência, tornando-se degradado e abandonado, e trazendo a necessidade de uma intervenção. Finalmente, o segundo equilíbrio surge: o centro revalorizado com uma política pública desenhada exclusivamente para ele. Nesse processo, ainda, há uma série de eventos em questão, como a construção da Associação Centro Vivo como um movimento de opinião visando ao convencimento da cidade de que era necessária uma intervenção ou a constituição de um grupo político que assume a gestão do governo local já motivado a implementar alguma política pública no mesmo sentido. Existem obstáculos no caminho, os quais apontam para uma interlocução entre esses dois movimentos, resultando na aprovação e criação do Alegra Centro, que passa a reverter o processo de degradação. Vale destacar, ainda, o diagnóstico elaborado: a causa da degradação é a queda da atividade econômica; nesse sentido, o desafio da intervenção seria conseguir atrair de volta ao centro negócios, vinculados à preservação dos imóveis ali construídos e que remetem aos tempos áureos da cidade.

Dentro das categorias de tramas que Czarniawska (2004) apresenta, essa história se encaixaria no Romance, no qual se apresenta certo heroísmo na ação dos dois atores principais - os empresários, vistos como a sociedade civil, e o governo local - os quais, unidos, passam a participar de uma saga pela recuperação, revalorização e revitalização do centro de Santos. A figura de linguagem presente, então, é a da metáfora: suas ações representam o triunfo da preservação da memória local, do passado singular que a cidade viveu, e que corria o risco de ser perdido, apagado. A história de Santos estaria salva no Alegra Centro.

Conforme ressaltado anteriormente, entretanto, essa narrativa não é, de maneira alguma, consensual. Mesmo suas partes, seus eventos críticos, encontram-se em debate nas diferentes narrativas. $E$ é justamente por meio das "micro-narrativas" que será possível propor a problematização dessa "macro-narrativa" do processo de elaboração do programa Alegra Centro.

\subsection{As micro-narrativas sobre a elaboração do programa Alegra Centro}

O olhar mais atento às narrativas sobre eventos específicos dentro do que se entende como o processo que levou à elaboração do programa Alegra Centro se faz indispensável para se alcançar os objetivos de (a) reconhecer as diferentes vozes presentes no campo-tema, (b) identificar pontos de fissura na macro-narrativa, (c) observar como e quais referências existem nas narrativas dos diferentes atores e (d) identificar pontos para problematização e análise posterior, então já estabelecendo diálogo com outros referenciais teóricos. Nesse patamar, ocorre a passagem da "reprodução" das narrativas em uma macronarrativa para sua "desconstrução", a partir das micro-narrativas. Para tanto, é possível reconhecer como parte das vozes dos atores também os diferentes documentos que foram entregues no momento das 
entrevistas, como reportagens de jornais e revistas, folhetos, leis e vídeos.

Cabe destacar, entretanto, que explorar o material levantado não podia significar perda de foco no desenvolvimento do presente trabalho: era preciso ter claro que a pergunta norteadora desta pesquisa era quais as perspectivas de público no processo de elaboração desta política pública. Dessa maneira, por mais que a "macro-narrativa" encontrada permitisse diferentes problematizações, indicando questões referentes a diversos campos do conhecimento, como a história, o urbanismo ou a geografia, optamos, aqui, por duas outras, que são bastante caras ao campo da administração pública: a interação entre governo e sociedade civil em contexto subnacional e o papel dos diferentes aspectos da cultura urbana local - patrimônio, memória, identidade - nas narrativas sobre este processo.

$\mathrm{Na}$ primeira questão, foi possível identificar uma série de fissuras. Em primeiro lugar, não há consenso sobre o ponto de início do processo de elaboração do programa Alegra Centro: se, por um lado, há o aparente reconhecimento de que todas as gestões municipais a partir de 1984 contribuíram para o início da "revitalização" do centro de Santos, por outro, há inconsistências quanto a quais ações lançaram as bases para o início do processo. Em determinadas narrativas, o ano de 1989 é citado como chave, em função da regulamentação de uma "subzona de interesse histórico e cultural" no centro da cidade, que teria inventariado os imóveis do centro da cidade e estabelecido níveis de proteção, prevendo isenção de IPTU (Imposto Predial e Territorial Urbano) para tais imóveis. Esse processo também é referido com menor importância, chegando a ser completamente inexistente em outras narrativas, as quais citam a revisão do Plano Diretor em 1998, por estabelecer as Áreas de Proteção Cultural além dos Níveis de Proteção, como a base para estabelecer um programa de "revitalização" para o centro.

As questões se tornam mais complexas quando os atores citam as razões para este processo. Ora estão relacionados a valores, como a dedicação em se estabelecer a proteção do patrimônio histórico local, ora aparecem referências a outras experiências, que inspiram a tomada de ação no âmbito municipal. Barcelona é exemplo constante nas narrativas para a intervenção; essa mesma experiência, no entanto, aparece com múltiplas faces: em algumas narrativas, ela é inspiração pela reestruturação na modernização do porto, negociada com os sindicatos dos trabalhadores portuários e impedindo o desemprego por meio de um programa de incentivo à abertura de pequenos comércios na região central daquela cidade - mais tarde constituída como polo turístico. Em outras, seu exemplo surge da revalorização imobiliária - como um fator positivo - de uma área degradada, como símbolo de uma "revitalização" ou "recuperação" de um espaço da cidade. Recife, Belém e Buenos Aires também são citadas frequentemente como exemplos para a intervenção em Santos.

Embora existam, basicamente, duas visões distintas, até aqui, sobre o processo, deve-se notar que ambas mencionam a participação da sociedade civil nesse processo, todas envolvendo, especificamente, os empresários e suas associações locais. Resta uma diferença: nas narrativas que contam 1989 como o início do processo, surge a referência à participação de sociedades de melhoramento dos bairros e de sindicatos; na outra, cuja base está em 1998, essa participação se dá por meio de reuniões nos 
conselhos municipais de desenvolvimento urbano (CMDU), de desenvolvimento econômico (CDES) e de defesa do patrimônio cultural local (CONDEPASA). Nessas visões, entretanto, o protagonismo é claramente reservado ao governo local. Os empresários locais, por sua vez, também viajam, tomam conhecimento de outras experiências e, da mesma maneira, também apresentam uma versão para o início do processo de elaboração da política pública. Esta estaria na articulação para a formação da Associação Centro Vivo, criada em 1994, reunindo 53 organizações, sendo que 45 delas aparecem no estatuto da entidade (ASSOCIAÇÃO CENTRO VIVO, 1994), referenciando nomes de atores específicos. Essa associação, por sua vez, tem seu início em um conselho de empresários formado com fins de embasar uma candidatura à prefeitura, que não se concretiza. Membros da ACV estiveram presentes nos mesmos três conselhos (CMDU, CDES e CONDEPASA), conforme as narrativas, e suas ações, que estiveram centradas em um movimento de opinião que buscava o convencimento da sociedade santista quanto à necessidade de uma política pública específica para o centro, estenderam-se até a criação do programa Alegra Centro, sendo que suas atividades foram encerradas em seguida, por acreditar-se que seu objetivo já havia sido alcançado.

Já para os moradores dos cortiços do centro, reunidos na Associação dos Cortiços do Centro (ACC), é narrada a sensação de serem o Entristece o Centro, em clara contraposição aos objetivos do programa Alegra Centro. A ACC foi criada em 1996, mas só passa a ter atuação mais efetiva na luta por direitos dessa população naquela região da cidade a partir de 2003 , conforme as narrativas, estando à parte de todo o processo de elaboração do programa.

$\mathrm{Na}$ segunda questão, referente à relação da política pública com os aspectos culturais, as narrativas revelaram um processo de (re)construção da história e da memória da cidade. Constantemente evocada para explicar o processo que levou à elaboração de uma política pública com o objetivo de "revitalizar" o centro, atores chegam a empreender a tentativa de recuperar toda a história da cidade, contando sobre o que identificam como seus momentos chaves: (a) sua fundação em função de condições geográficas que propiciavam um porto natural; (b) a construção da ferrovia por meio da São Paulo Railway Company, ligação do porto de Santos com área de produção de café, situada no planalto; (c) o acentuado crescimento populacional e econômico, fruto do comércio do café, entre o fim do século XIX e o início do século XX; (d) a mudança de vocação da região com a consolidação do polo petroquímico em Cubatão através da COSIPA; e (e) a intervenção militar na cidade que causa a queda de suas atividades econômicas, levando-a de segundo para oitavo lugar entre as economias do Estado.

É possível perceber, também a partir das narrativas, o surgimento de um símbolo, que percorre diferentes momentos dessa história da cidade - ou ainda, que conecta o presente ao passado: o bonde. Nesse sentido, notase a construção de uma narrativa específica sobre sua relação com a cidade. Os diferentes atores, tanto empresários como membros da ACC, contaram frequentemente sobre quando, ainda adolescentes, usavam o bonde como meio de transporte pela cidade, que os levava ao centro, seja para estudar ou para consumir - ressaltando a oferta de serviços que antes se encontrava concentrada naquela região da cidade, trazendo a impressão, comum a todas essas narrativas, de que a lembrança do bonde 
transporta-os automaticamente aos "velhos bons tempos.' O evento que decidiria, contudo, pela extinção do uso do bonde como meio de transporte local teria partido do governo militar: atores mencionam que quase todos os bondes da cidade foram "destruídos a marretadas pelos militares", com o fim de que "nunca mais voltassem a circular" por Santos, sendo substituídos pelos ônibus e deixando maior espaço para o transporte individual por meio dos carros.

A volta do bonde às ruas de Santos é reconhecida como mérito das recentes intervenções no centro, que culminaram no programa Alegra Centro, a partir de 1997, chegando a ser identificado por diversos atores como o símbolo da revitalização da região. Uma das narrativas é bastante interessante para o exame dessa questão, em virtude de se apresentar na forma de uma história contada por meio de eventos críticos ordenados cronologicamente, passando de um estado de equilíbrio para outro: o bonde estava desativado das ruas de Santos como meio de transporte e havia um exemplar que necessitava de reparos, funcionando, parado, como posto de informações turísticas na região das praias; o ex-secretário municipal sugere o reparo desse equipamento ao então presidente da companhia de tráfego local, CET - que, mais tarde, se tornaria chefe do poder executivo local - e este aceita o desafio, utilizando a mão de obra daquela organização, que ainda apresentava funcionários em seus quadros que haviam trabalhado com os bondes, décadas atrás. Após o sucesso desse reparo, conta-se sobre o projeto de revitalizar o centro, que já estaria em curso, sugerindo-se que o bonde voltasse a circular pelas ruas daquele bairro, "amarrando" o "acervo" de patrimônio histórico que a cidade dispunha, construindo uma rota turística. $\mathrm{O}$ então presidente da companhia local aprova a ideia e, juntos, levam-na ao então prefeito, que passa a colocar esse assunto como prioridade de governo, até que a rota é efetivamente inaugurada no ano 2000.

Dessa maneira, observa-se que 0 bonde passa a ganhar outro sentido, para além de um meio de transporte: ele passa a conduzir seus visitantes por um roteiro turístico construído pelas ruas do centro, atribuindo uma ideia de conjunto ao patrimônio históricoarquitetônico local. Mais que isso: ele mesmo passa a ser um personagem, que empreende ações, nesse processo. Consequentemente, a própria história da cidade também é (re) construída, tendo-se o bonde como o símbolo consensual da identidade santista, capaz de reunir os diferentes grupos sociais que compõem a cidade e que se encontravam em conflito - ou distanciados. Trata-se de um forte indicativo de que o processo de elaboração da política de revitalização do centro envolve também a mobilização e valorização de pontos específicos da cultura local, sejam eles o patrimônio arquitetônico, a história, a memória ou a identidade. E, nesse sentido, também desempenham papel relevante na discussão sobre as perspectivas de público presentes no processo de elaboração dessa política pública.

\section{CONSIDERAÇÕES FINAIS: CONTRIBUIÇÕES PARA FUTUROS ESTUDOS}

A pergunta de pesquisa adotada, ao mesmo tempo em que aparece como ponto de partida desta pesquisa, também é seu ponto de chegada - em coerência com o que fora colocado, anteriormente, como objetivo da pesquisa, ou seja, a construção de um enredo de suspense, de um mistério. 
Para fundamentá-la, tivemos como base, de um lado, os estudos de Frederickson (1997) que, partindo do reconhecimento de que não é consensual o "como", o "porquê" e o "para que" das ações da Administração Pública, não só identifica cinco perspectivas básicas de público ${ }^{1}$, como também constrói conceitos que fundamentam seu espírito da administração pública. Esta, por sua vez, teria como características a impessoalidade, o convívio entre os diferentes e a qualidade dos espaços públicos - aqui entendido como estando efetivamente aberto à participação de todos os interessados. Tratase de indicações importantes para futuras análises do processo, tornando possível estabelecer relações com contribuições de outros autores (tais como BAUMAN, 2005; LEITE, 2004; OLIVEIRA, 2002; RIZEK, 2007 e SENNETT, 1994), tendo em vista a análise desses aspectos no processo narrado.

Harvey (2003) fornece outra possibilidade interessante para eventuais desdobramentos deste trabalho. Sua perspectiva da competição entre cidades por fluxos de investimentos e turistas, contexto no qual as cidades, vistas como empresas, buscam diferenciar-se uma das outras, instrumentalizando aspectos culturais locais porque únicos e singulares, é crucial para problematizar quem se beneficia desses processos e quais memórias, histórias e identidades são preservadas e quais são esquecidas - reconhecendo-se que as cidades são construídas por múltiplas contribuições de diferentes grupos sociais ao longo do tempo. Essa abordagem também pode servir como fio condutor para discutir outras questões, como a estetização da cidade (FEATHERSTONE, 1995; FORTUNA, 1997; LEITE, 2004), a cidade como mercadoria (ARANTES, 2000) e a reconstrução das identidades locais
(DECCA, 2002; SUBIRATS; RIUS, 2008).

Dessa maneira, é possível apontar como contribuições deste trabalho a demonstração da capacidade do instrumento de estudo de narrativas como meio para se reconhecer a complexidade do campo-tema, e, nesse sentido, das políticas públicas que são objeto de nossos estudos, reconhecendo e mapeando questões de pesquisa em diálogo com os atores que com elas se relacionam no cotidiano, ao mesmo tempo em que levantam problemas relevantes para análise posterior. É possível observar que essa característica vem sendo progressivamente reconhecida no campo, mesmo na prática da gestão pública: a própria noção de inovação (SPINK, 2004) ou das novas formas de governar (BRUGUÉ; GOMÁ, 2008) traz em sua esteira, como um de seus componentes, a capacidade de se vislumbrar ações que sejam transversais, envolvendo a articulação entre diferentes atores ou ainda novos arranjos institucionais - embora, na questão da inovação, essas articulações sejam vistas mais como "parte pragmática da ação e não a inovação em si" (SPINK, 2004, p. 7). Tratase do reconhecimento de que os problemas não são setoriais e da necessidade de se construir diálogos coletivos mais amplos, transdisciplinares, transversais.

A setorialidade no estudo de políticas públicas é apontada mesmo como um dos problemas que enfrenta atualmente esse campo de estudo, assim como a escassa acumulação de conhecimento na área e o excessivo foco nos órgãos governamentais (SOUZA, 2003). Nesse sentido, a opção por se estudar as diferentes perspectivas de público presentes nas narrativas sobre o processo de elaboração de um caso específico de política pública se revelou interessante para construir conhecimento em diálogo - e não à parte com os diferentes atores que se relacionam 
Estudo de políticas públicas a partir de narrativas: o caso do processo de elaboração do Programa de Revitalização e Desenvolvimento da Região Central Histórica de Santos

com nossos temas de pesquisa no cotidiano. Além disso, construir como problematização as diferentes perspectivas sobre o público presentes e não presentes em dinâmicas de políticas públicas pode ser útil para os governos locais que implementam programas como o estudado nesta pesquisa. Uma contribuição deste trabalho, portanto, também pode ser propor que se pense em maneiras de ampliar a noção de público nos processos de elaboração de políticas públicas, superando as relações pessoais e ampliando o debate para a participação de diferentes atores, grupos sociais ou cidadãos, propiciando o encontro entre os diferentes nessas dinâmicas, tornando-as plurais.

\section{REFERÊNCIAS BIBLIOGRÁFICAS}

ALVES, M. A. Terceiro setor: as origens do conceito. In: ENCONTRO NACIONAL DA ASSOCIAÇÃO NACIONAL DE PÓS-GRADUAÇÃO E PESQUISA EM ADMINISTRAÇÃO, 26, 2002, Salvador. Anais.

. O conceito de sociedade civil: em busca de uma repolitização. Organização \& Sociedade, v. 11, n. 30, pp. 141-154, 2004.

ALVES, M. A; BLIKSTEIN, I. Análise da narrativa. In: GODOI, C. K; BANDEIRA-DEMELLO, R; SILVA, A. B. (Orgs) Pesquisa qualitativa em estudos organizacionais: paradigmas, estratégias e métodos. São Paulo: Saraiva, 2006.

\section{ALVESSON, M; KÄRREMAN, D.} Constructing mistery: empirical matters in theory development. Academy of Management Review, v. 32, n. 4, pp. 12651281, 2007.

ARANTES, O. Uma estratégia fatal: a cultura nas novas gestões urbanas. In: ARANTES, O; VAINER, C; MARICATO, E. (Orgs) A cidade do pensamento único: desmanchando consensos. Petrópolis: Vozes, 2000.

ASSOCIAÇÃO CENTRO VIVO. Estatuto da Associação Centro Vivo, Sociedade PróRevalorização do Centro de Santos. Santos: autor, 1994.

BAUMAN, Z. Confiança e medo na cidade. Lisboa: Relógio D’Água, 2005.

BRUGUÉ, Q; GOMÁ, R. Novas formas de governar: limites e oportunidades. In: Respostas locais a inseguranças globais: inovação e mudança no Brasil e Espanha. (pp. 260-279). Barcelona: Fundação CIDOB, 2008.

CZARNIAWSKA, B. The uses of narrative in Organization Research (Relatório de Pesquisa/2000: 5), Gothenburg, Gothenburg Research Institute - School of Economics and Commercial Law, Göteborg University, 2000.

\section{Narratives in Social Science}

Research. London: SAGE, 2004.

DECCA, E. S. de. Cidadão, mostre-me a 
identidade! In Cadernos CEDES, v. 22, n. 58, pp. 7-20, 2002.

FEATHERSTONE, M. Cultura de Consumo e Pós-Modernismo. São Paulo: Studio Nobel, 1995.

FARAH, M. F. S. Administração pública e políticas públicas. Revista de Administração Pública, v. 45, n. 3, pp. 813-836, 2011.

FISCHER, F. Beyond empiricism: policy inquiry in postpositivist perspective. Policy Studies Journal, v. 26, n. 1, pp. 129-146, 1998.

FORTUNA, C. As cidades e as identidades narrativas, patrimônios e memórias. Revista Brasileira de Ciências Sociais, v. 12, n. 33, pp. 127-141, 1997.

FREDERICKSON, H. G. The spirit of public administration. San Francisco: Jossey-Bass, 1997.

HARVEY, D. A arte de lucrar: globalização, monopólioeexploraçãodacultura.In:MORAES, D. (Org) Por uma outra comunicação: mídia, mundialização cultural e poder (pp. 139-171). Rio de Janeiro: Record, 2003.

SONHOS (Dreams/Yume). Direção: Akira Kurosawa e Ishirô Honda. Produção: Mike Y. Inoue e Hisao Kurosawa. Roteiro: Akira Kurosawa. Estados Unidos/Japão: Warner Bros, 1990. 1 DVD.
LEITE, R.P. Contra-Usos da cidade: lugares e espaço público na experiência urbana contemporânea. Campinas: UNICAMP, 2004.

OLIVEIRA, F. de. Aproximações ao Enigma: o que é Desenvolvimento Local? In: CACCIA-BAVA, S; PAULICS, V; SPINK, P. (Orgs) Novos Contornos da gestão local: conceitos em construção (pp. 11-31). São Paulo: Polis, 2002.

REVEL, J. (Org). Jogos de escala: a experiência da microanálise. Rio de Janeiro: Fundação Getulio Vargas, 1998.

RIZEK, C. S. São Paulo: orçamento e participação. In OLIVEIRA, F. de; RIZEK, C. S. (Orgs). A era da indeterminação. São Paulo: Boitempo, 2007.

SARAVIA, E. Introdução à teoria da política pública. In: SARAVIA, E; FERRAREZI, E. (Orgs). Políticas públicas; coletânea. Brasília: ENAP, 2006.

SENNETT, R. Carne y Piedra: el cuerpo y la ciudad en la civilización occidental. Madrid: Alianza Editorial, 1994.

SNOW, D. A; SOULE, S. A. A primer on social movements. New York: W. W. Norton, 2009.

SOUZA, C. "Estado do campo" da pesquisa 
em políticas públicas no Brasil. Revista Brasileira de Ciências Sociais, v. 18, n. 51, pp. 15-20, 2003.

SPINK, P. K. Pesquisa de campo em psicologia social: uma perspectiva pósconstrucionista. Psicologia e Sociedade, v. 15, n. 2, pp. 18-42, 2003.

A inovação na perspectiva dos inovadores. In: CONGRESO INTERNACIONAL DEL CENTRO LATINOAMERICANO DE ADMINISTRACIÓNPARAELDESARROLLO SOBRE LA REFORMA DEL ESTADO Y DE LA ADMINISTRACIÓN PÚBLICA, 9, 2004, Madri, Espanha. Anais.
SUBIRATS, J; RIUS, J. Del Xino al Raval. Barcelona: Hacer Editorial, 2008.

\section{Notas}

1) Sendo elas: (1) a pluralista, na qual o público seria baseado no resultado da atuação de diferentes grupos de interesse; (2) da escolha racional, em que o público seria a soma dos interesses privados; (3) a legislativa, na qual o público estaria representado nos políticos eleitos ocupando instituições; (4) a do cliente, em que o público seriam os consumidores de serviços públicos, fazendo referência à street level bureaucracy; e (5) a do cidadão, em que o público estaria na participação direta de cidadãos bem informados em questões públicas com foco para além de seus interesses individuais (FREDERICKSON, 1997). 